7. Reprod. Fertil. (1965) 9, 19-27

\title{
ARTERIES AND VEINS OF THE INTERNAL GENITALIA OF FEMALE SWINE
}

\author{
S. L. OXENREIDER, R. G. MaCLURE AND B. N. DAY \\ Missouri Agricultural Experiment Station, Departments of Animal Husbandry and School \\ of Veterinary Medicine, Department of Veterinary Anatomy, Columbia, Missouri, U.S.A.
}

(Received 22nd May 1964)

Summary. The angioarchitecture of the internal genitalia of twenty-six female swine was studied. The arteries of the genitalia of female swine anastomose freely allowing fluid injected into one artery to flow into all other arteries of the genitalia. A similar degree of anastomosis exists in the veins.

There is no branch to the uterine horn from the so-called uteroovarian artery and a more descriptive name for the artery would be ovarian. Also, it is more appropriate to refer to the artery originating from the umbilical artery as the uterine instead of middle uterine artery since it supplies the entire uterine horn and there is no cranial uterine artery in the pig. The uterine branch of the urogenital artery supplies the cervix and uterine body.

Two large veins are located bilaterally in the mesometrium of the uterus. The larger is nearer the uterine horn, runs the entire length of the horn and is a utero-ovarian vein. It follows the ovarian artery after receiving one or two venous branches from the ovary. An additional large vein which parallels the utero-ovarian vein in the mesometrium is designated as the uterine vein since it follows the uterine artery. The uterine vein anastomoses with the utero-ovarian vein through one large branch and many smaller branches and enters a ureteric vein as the uterine artery crosses the ureter. The uterine body and cervix are drained by the uterine branch of the urogenital vein.

\section{INTRODUCTION}

Recent studies in swine reproduction on ovarian and uterine functions during the oestrous cycle and pregnancy indicate the need for a more thorough understanding of the angioarchitecture of the female genitalia. Contemporary anatomical texts fail to present a detailed description of the blood vascular system of the genitalia of female swine (Sisson \& Grossman, 1953; Getty, 1955; St Clair, 1958).

Lange (1959) and Barone, Pavaux \& Frapart (1962) studied the vascular system of the swine uterus in order to resolve contradictions of existing data concerning the arterial and venous supply of the uterus and ovaries. Lange proposed the following changes in nomenclature: (1) ovarian artery instead of 
utero-ovarian artery; (2) uterine artery instead of middle uterine artery and (3) uterine branch of vaginal (urogenital or urethrogenital) artery instead of caudal uterine artery. This nomenclature was also introduced by Preuss (1959). Lange stated that the veins followed the arteries and that the ovarian vein also participated in draining the uterus.

Hansel \& Asdell (1951) studied the arterial supply of cattle uteri by injecting vinyl acetate into the arteries and digesting the tissue away with acid, leaving arterial casts. Reuber \& Emmerson (1959) injected the utero-ovarian and middle uterine arteries of cattle uteri with a radiopaque compound and obtained radiographs of the arterial supply of the internal genitalia. Radiographs have the advantage of showing the vessels in relationship to the tissue in a permanent record. Vinyl casts, however, are firmer at room temperature, allowing vessels to be followed by gross dissection.

The present study was undertaken to determine the paths taken by the arteries and veins of the uterus, uterine tubes (oviducts) and ovaries, and to create reference maps of arteries and veins to be used in research and surgical procedures. An additional objective of this study was to examine cyclical changes in the arterial supply of the internal genitalia.

\section{MATERIAL AND METHODS}

\section{ANIMALS}

Ten Hampshire and Duroc gilts that were 8 to 12 months of age and weighed between 250 and $350 \mathrm{lb}$ were used in a study of the arterial supply of the internal genitalia. Radiographic and corrosion cast techniques were used. Five groups of two gilts each were studied according to the following stages of the oestrous cycle:

Group 1 -oestrus (Days 1 and 2 of oestrous cycle with Day 1 being the first day of oestrus).

Group 2-metoestrus (Day 5, developing corpora lutea).

Group 3-dioestrus (Days 10 and 11, mature corpora lutea).

Group 4-dioestrus (Days 15 and 16, corpora lutea starting to regress).

Group 5-pro-oestrus (Days 20 and 21, follicles well developed).

Six gilts of similar age and weight were used to study the venous system by means of radiographs and corrosion casts. The arteries and veins of the reproductive tracts of four additional sexually-mature gilts were dissected and probed shortly after slaughter. Three immature gilts were examined immediately following slaughter and three immature gilts were embalmed and singly injected via the common carotid artery before being examined.

\section{INJECTION PROCEDURE}

In those animals injected with latex and radiopaque media, the viscera were severed close to their mesenteric attachments in the carcass to preserve the origins of the arteries and veins from the abdominal arterial and venous trunks. The genitalia, bladder, rectum and perineum were removed from the remaining 
viscera and placed in a pan of warm water $\left(120\right.$ to $\left.150^{\circ} \mathrm{F}\right)$. The temperature of the water was maintained at this level while the vessels were being injected.

One reproductive tract from each of Groups 2 to 5 was injected by the method and with a similar gelatin injection mass used by Reuber \& Emmerson (1959). The present procedure differed only in the substitution of bismuth subcarbonate for bismuth subnitrate in the injection mass and in the use of less volume of injection mass in the ovarian artery.

One reproductive tract from each of Groups 2 to 5 , the two tracts from Group 1 and the reproductive tracts used to study the venous supply were injected with an injection mass containing four parts pigmented latex to one part Micropaque. This mixture, which was similar to that reported by Tobin (1944), was injected into the uterine arteries after the ovarian arteries had been injected with the Reuber injection mass. As a result the arteries and arterioles in the ovaries were injected with the deeper penetrating mass, and the latex compound was retained in the large arteries. The latex-Micropaque mixture made it possible to obtain a satisfactory radiograph and corrosion cast on the same sample. In those tracts in which the veins were injected, the uterine branch of the urogenital (urethrogenital or vaginal) vein was found to be most satisfactory as an injection site.

After being injected, each specimen was placed in a refrigerator to cool and harden. When the injection mass had hardened, the rectum, vagina and deposits of adipose and connective tissue were removed from the genitalia. After radiographs were taken, the genitalia were either dissected or arterial casts were made by soaking the genitalia in a $1: 1$ mixture of water and hydrochloric acid for 2 or 3 days and washing the softened tissue from the injection mass with gently running water. Several of the casts were dried and mounted in clear plastic blocks.

\section{RESULTS}

The arteries supplying the ovaries and uterus (ovarian, uterine and uterine branch of the urogenital) were found to form many anastomoses. An arterial network was thus formed whereby fluid entering one of the arteries would travel into all arteries of the internal genitalia. To describe the contributions of individual arteries to the internal genitalia, the nomenclature proposed by Preuss (1959) and Lange (1959) will be followed.

The veins draining the ovaries and uterus (utero-ovarian, uterine, and uterine branch of the urogenital) were also found to communicate freely, allowing fluid injected into one vein to travel into all other veins of the internal genitalia. The nomenclature of the veins will be the same as the arteries they follow with the exception that the vein following the ovarian artery will be called the uteroovarian vein.

\section{OVARIAN ARTERY}

The ovarian arteries were found to originate from the aorta, run straight caudally and ventrally for about $8 \mathrm{~cm}$ and divide into several coiled branches. The coiling formed a plexus of about $4 \mathrm{~cm}$ in length cranial and dorsal to the 
ovary (Pl. 1, Fig. 1). Branches of this plexus were followed into the ovary, mesosalpinx and uterine tube. Minute branches also anastomosed freely with three or four small branches from the uterine artery, but in no case was a direct branch to the uterine horn from the ovarian artery isolated.

\section{UTERINE ARTERY}

A uterine artery originated from the umbilical artery shortly after the latter left the internal iliac artery (Text-figs. 1 and 2). The uterine artery was found to divide into two (three cases) or three (seventeen cases) main branches. These primary branches divided into several arborizing rami that communicated with each other in the broad ligament near the mesometrial border of the uterine

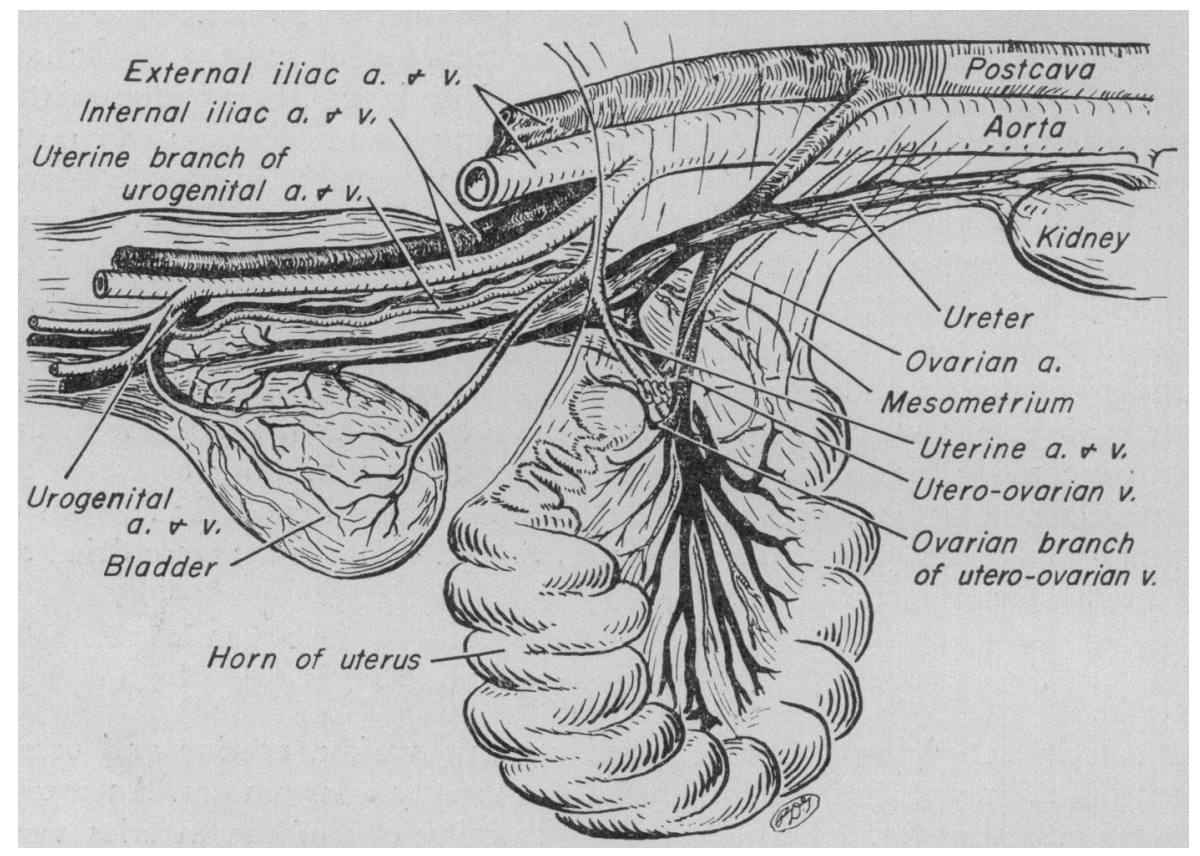

TEXT-FIG. 1. Lateral view of arteries and veins of internal genitalia.

horn. A vessel formed from these anastomoses ran the entire length of the uterine horn giving off many small branches to the uterus. These branches bifurcated at the mesometrial border and sent rami to perforate the myometrium on either side of the uterine horn (Pl. 1, Figs. 1 and 2). An arterial plexus was formed in the myometrium from which arterioles supplied the endometrium.

The main trunk of the uterine artery and its most lateral branch were observed to give off three or four branches that divided into many small anastomotic branches to the ovarian arterial plexus and the mesosalpinx (Pl. 1, Fig. 2). Some of these branches were traced through many anastomoses with branches of the ovarian artery to the hilus of the ovary. At least one main branch from the ovarian artery and four to sixteen small branches, which were 


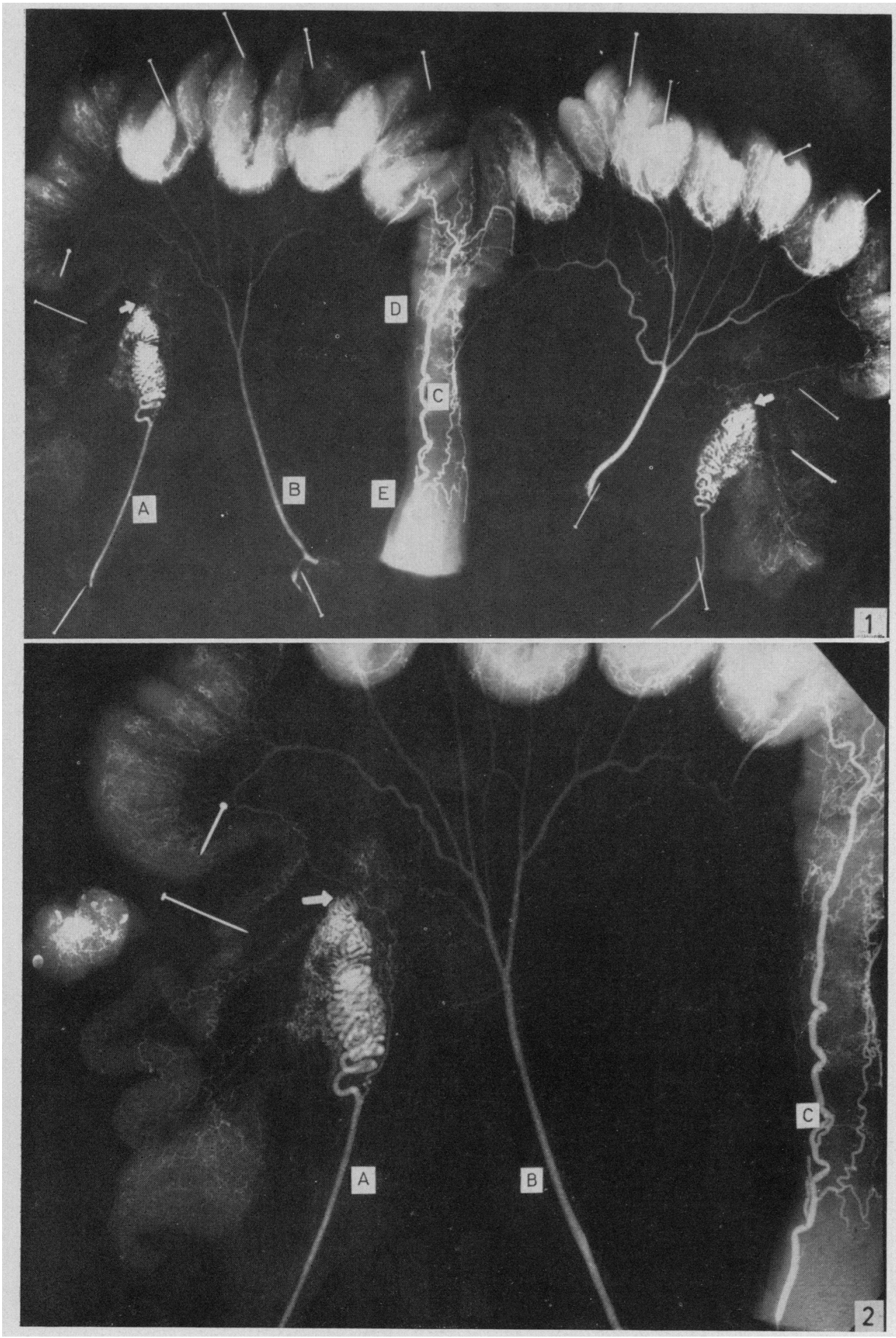

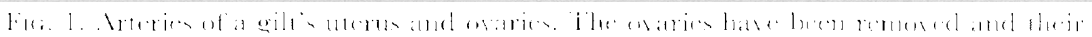

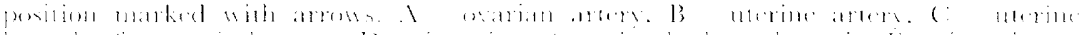

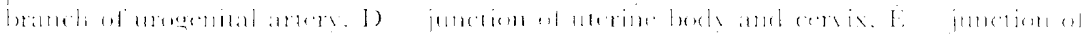
corvis allel beritat.

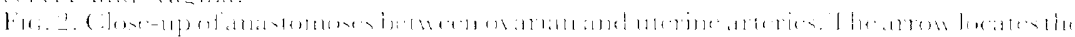

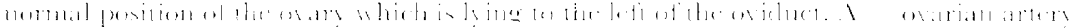

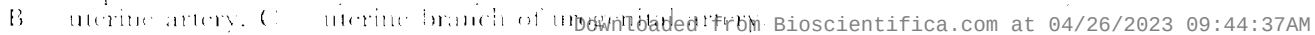



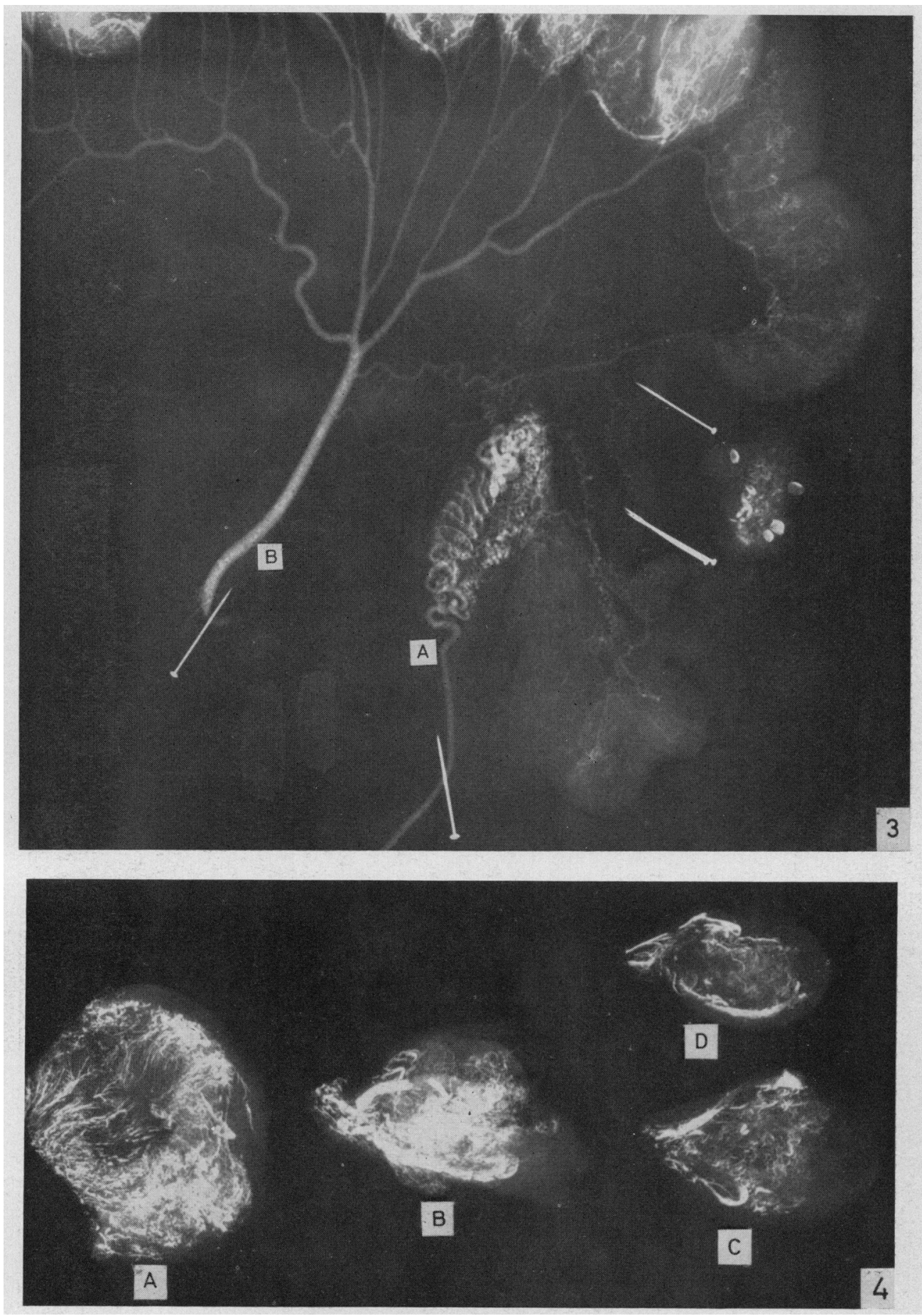

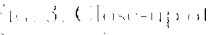

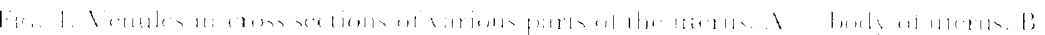

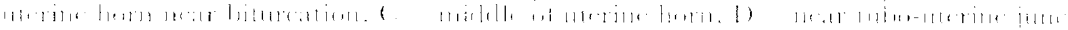

$: i 11\}$ 


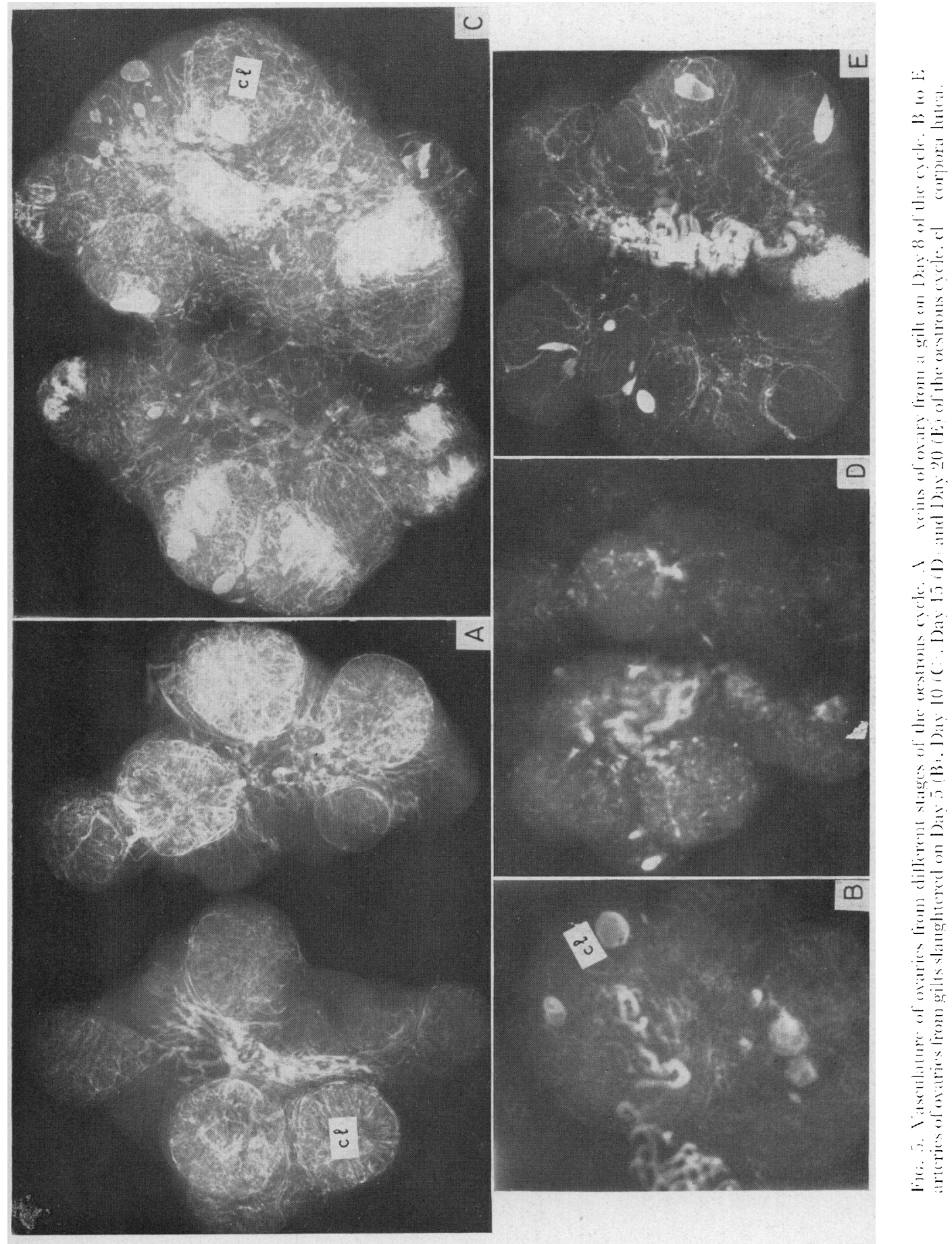



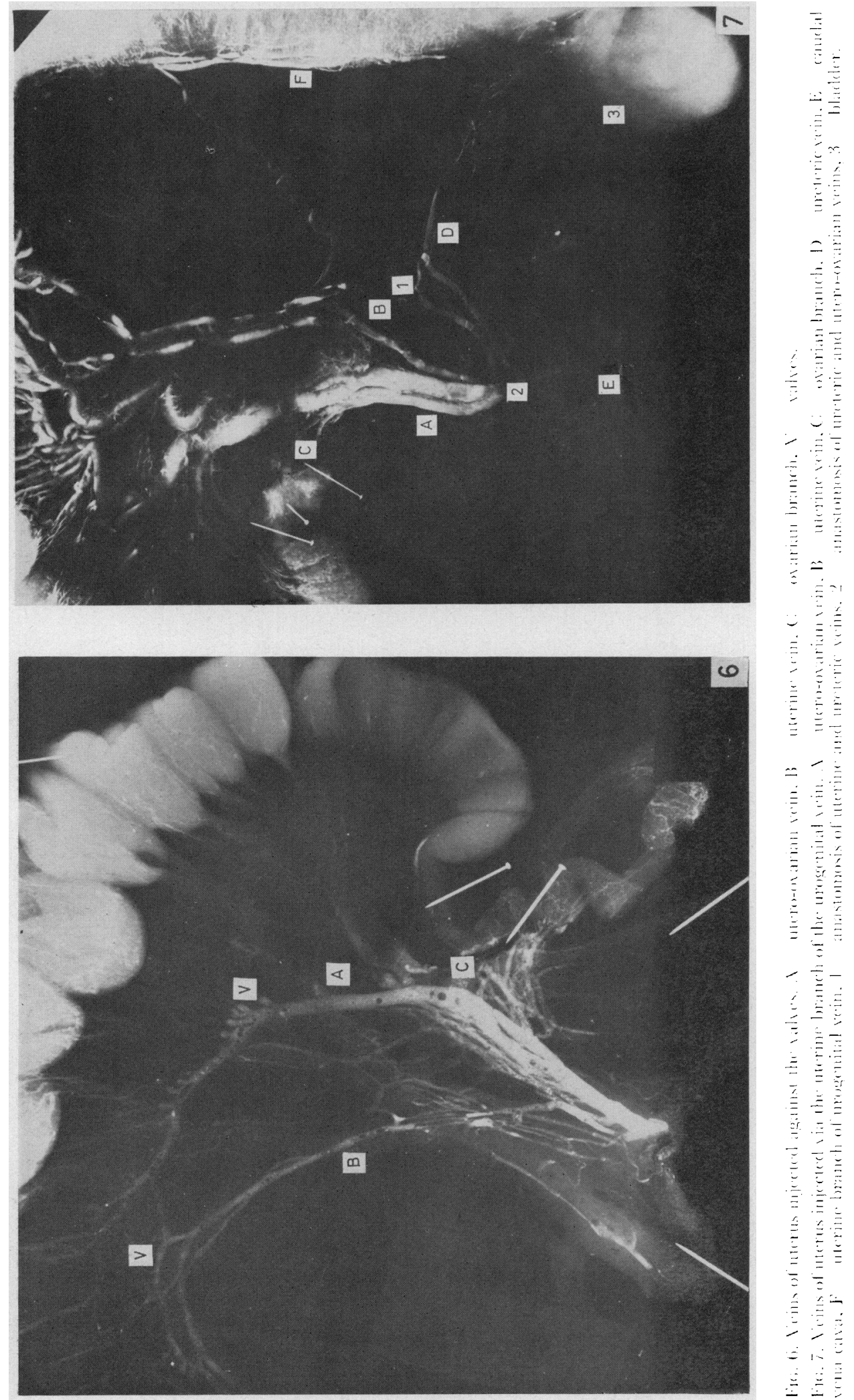
the result of anastomoses between the ovarian and uterine arteries, were found to enter the ovary.

In all animals, a branch from the uterine artery was observed to travel to the tubo-uterine junction and bifurcate with one branch supplying the uterine tube and the second branch fusing with a separate uterine branch along the uterine horn. The tubo-uterine ramus was sometimes the most lateral main branch of the uterine artery but at other times was a branch of the lateral main branch or a small branch of the uterine artery itself. In one case, shown in Pl. 1, Fig. 2, a small arterial branch left the ovarian artery prior to the plexus and

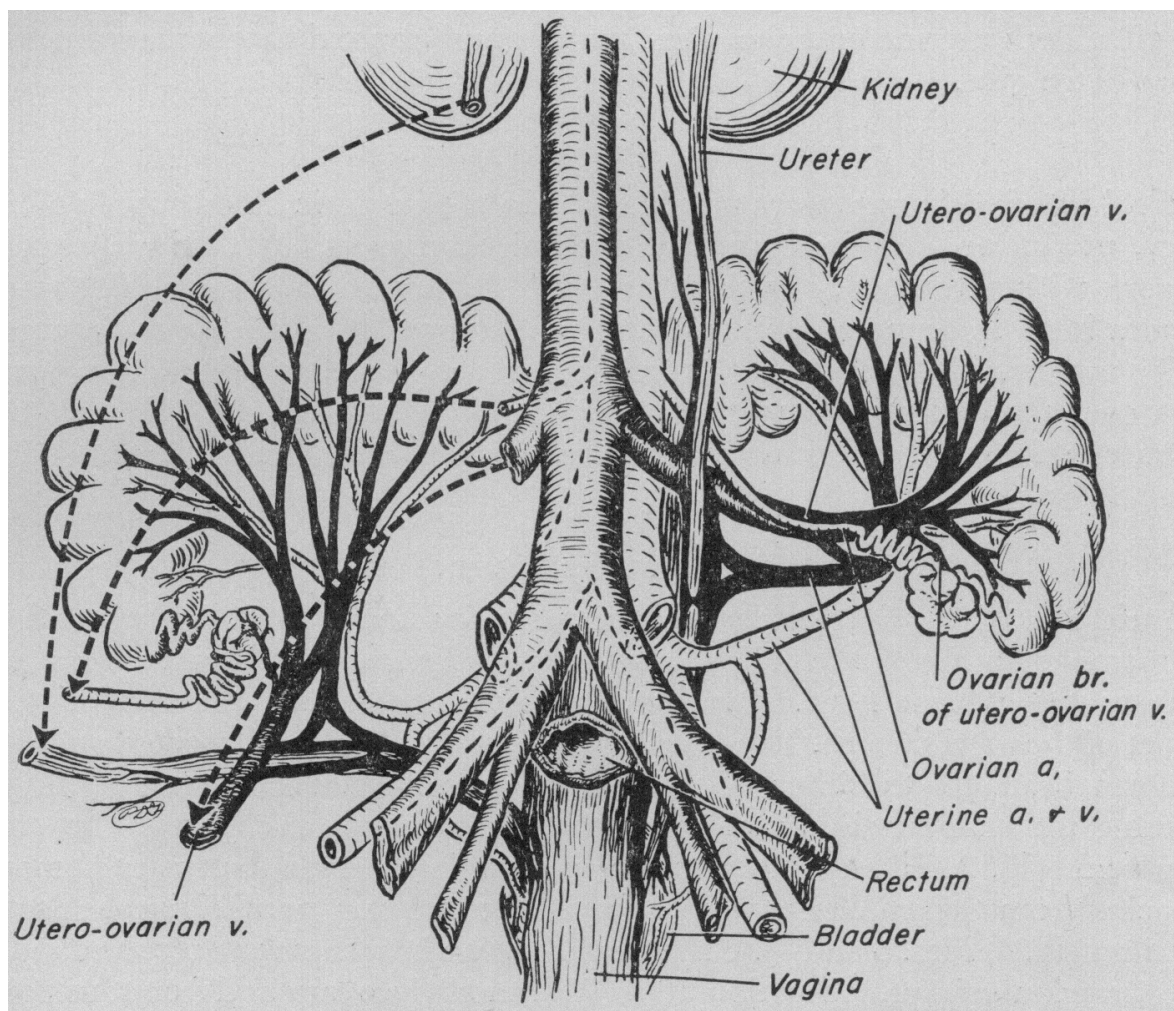

TEXT-FIG. 2. Dorsal view of arteries and veins of internal genitalia.

bifurcated on the isthmus of the uterine tube. One of its branches travelled toward the ampulla of the uterine tube and the other joined a branch of the uterine artery before it reached the tubo-uterine junction. In all other cases the arterial supply to the isthmic portion of the uterine tube originated from the uterine artery as in Pl. 2, Fig. 3. Ovarian and uterine arterial branches anastomosed freely in the mesosalpinx of the ampullar portion of the uterine tube.

\section{UTERINE BRANCH OF UROGENITAL ARTERY}

The uterine branch of the urogenital (urethrogenital or vaginal) artery originated from the urogenital artery shortly after the latter left the internal iliac (Text-fig. 1). The uterine branch was found to run forward giving off rami 
to the cervix before entering the ventral part of the body of the uterus. The uterine branch received a vessel from the medial branch of the uterine artery at a variable position on the cervix. In eight of ten gilts, one uterine branch of the urogenital artery dominated the blood supply of the cervix and uterine body and divided at the beginning of the uterine horns into the left and right branches. Each branch followed its respective uterine horn and anastomosed directly with a branch of the uterine artery. The uterine branch of the opposite side was either absent or was reduced in size and anastomosed with the larger uterine branch before the latter bifurcated as in Pl. 1, Fig. 1. The left uterine branch was larger in six gilts and the right branch was larger in two gilts. Both uterine branches were present and approximately the same size in two of ten gilts.

\section{GYCLIGAL CHANGES IN VASCULARITY}

Cyclical arterial changes were not detected in the extrinsic blood supply of the ovary, uterine tube and uterus, but cyclical changes in the intrinsic arterial network within the ovary were observed. The large number of follicles and corpora lutea in swine made it difficult to interpret in detail the radiographs of the ovaries, but the greater vascularity of ten- or eleven-day-old corpora lutea over those of other stages of the cycle was apparent (Pl. 3, Fig. 5). An increase in size of arterioles supplying follicles was observed during the follicular phase of the cycle.

\section{UTERO-OVARIAN VEIN}

The utero-ovarian vein, designated as ovarian by Lange (1959), originated in the mesometrium near the body of the uterus and traversed the entire length of its respective uterine horn. It received many branches from the mesometrial border of the uterine horn. The distal ends of these branches bifurcated and sent arciform branches to either side of the uterine horn. Innumerable venules draining the endometrium perforated the myometrium and joined the arciform veins (Pl. 2, Fig. 4). The utero-ovarian vein received many anastomotic branches from the smaller uterine vein as the two ran parallel in the mesometrium (Pl. 4, Figs. 6 and 7). One or two ovarian branches were received as the utero-ovarian vein passed within 10 to $20 \mathrm{~mm}$ of the ovary and from this point the utero-ovarian vein followed the ovarian artery medially and cranially. Branches from the uterine tube entered either the ovarian branches or the utero-ovarian vein directly. Only three or four venous branches could be found at the hilus of the ovary and these soon joined to form one or two ovarian branches. Veins from the mesosalpinx appeared to enter the ovary and establish a portal system but upon careful inspection it was revealed that the ovary is attached to the broad ligaments, in which the veins are located, by a 5 to $10 \mathrm{~mm}$ extension of mesovarium (Text-fig. 3). The only vessels located in this portion of the mesovarium were several arterial branches supplying the ovary and venous branches draining the ovary.

Just prior to entering the caudal vena cava (postcava), at the level of origin of the ovarian artery from the abdominal aorta, the utero-ovarian vein received branches from veins following the ureter. Branches were received from both the 
cranial and the caudal portion of the ureter. The cranial veins drained the proximal part of the ureter and the parietal peritoneum in that area. The caudal veins drained the distal portion of the ureter and received the cranial vesical veins from the lateral ligaments of the bladder and the uterine vein from the mesometrium (Text-figs. 1 and 2).

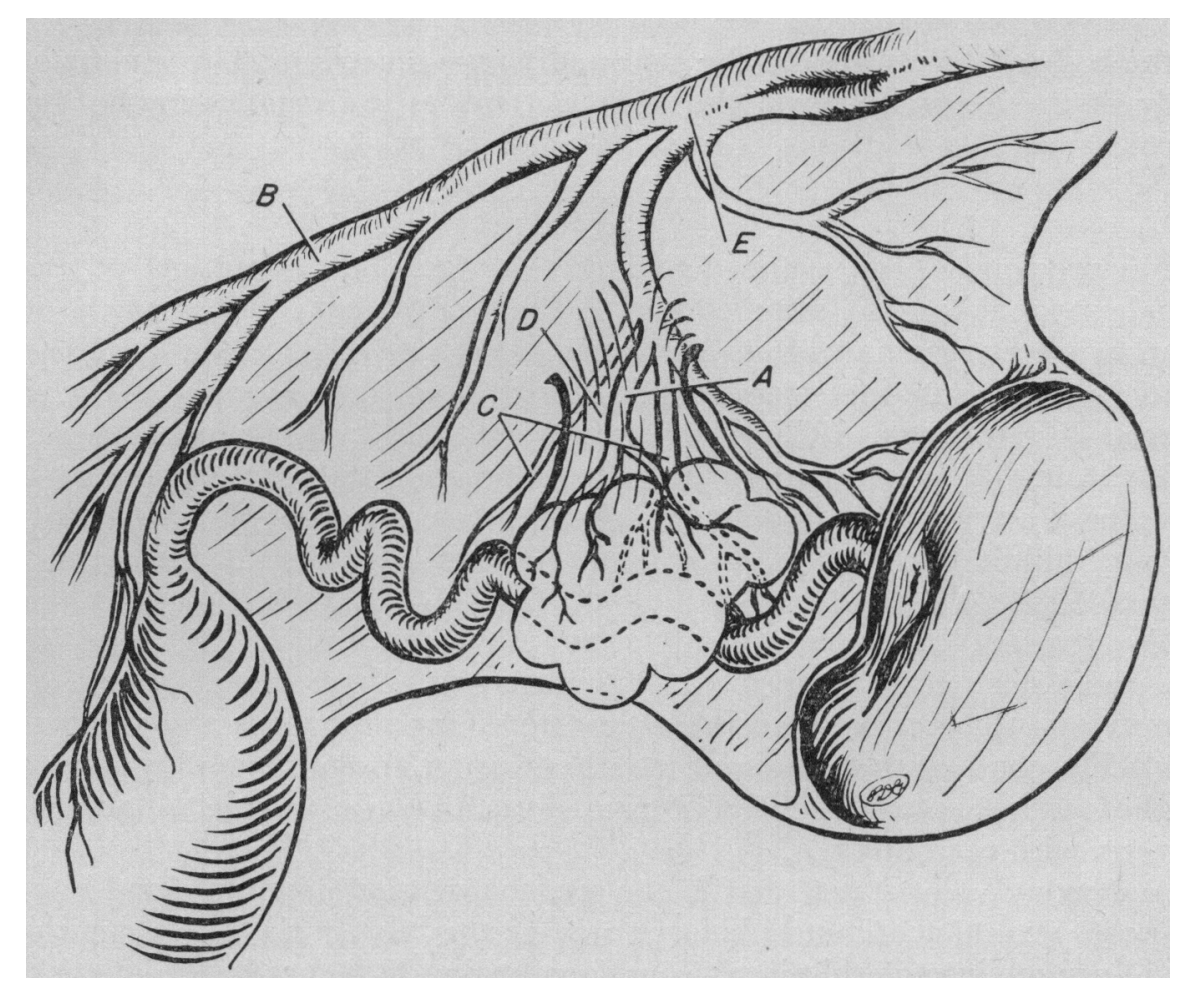

TEXT-FIG. 3. Veins in the area of the ovary. $A=$ ovarian branch of utero-ovarian vein, $\mathrm{B}=$ uterine branch of utero-ovarian vein, $\mathrm{C}=$ tubal branches, $\mathrm{D}=$ mesovarium, $\mathrm{E}=\mathrm{utero-ovarian}$ vein.

\section{UTERINE VEIN}

A second significant, but smaller, vein of the uterus was found lying parallel to the utero-ovarian in the mesometrium (Pl. 4, Figs. 6 and 7). It was located higher in the mesometrium than the utero-ovarian vein and it received branches from the caudal one-half to two-thirds of the uterine horn that were parallel to the branches emptying into the utero-ovarian vein. The uterine vein divided into two branches approximately equal in size. One branch anastomosed with the utero-ovarian vein a variable distance proximal to the ovarian ramus and the other branch followed the uterine artery. The uterine and utero-ovarian veins communicated by two or three anastomotic branches as the uterine vein followed the uterine artery. The uterine vein left the path of the uterine artery as the artery crossed the ureter and the vein entered one of two veins which followed the ureter as shown in Pl. 4, Fig. 7. Small venous branches draining the 
lateral ligaments of the bladder and the mesometrium also joined the uterine vein.

UTERINE BRANCH OF UROGENITAL VEIN

This vein followed the artery of the same name and joined the urogenital vein which emptied into the internal iliac vein. The uterine branch of the urogenital vein anastomosed freely with both the utero-ovarian and uterine veins in the body of the uterus and the surrounding mesometrium. The venules of the body of the uterus followed the same pattern as the venules in the uterine horns.

\section{DISGUSSION}

It has previously been assumed that the arteries of the reproductive tract of female swine follow the same pattern as those of the cow. In the cow a uteroovarian artery originates from the aorta and sends at least one large uterine branch (cranial uterine artery) to the uterine horn before supplying the ovary (Sisson \& Grossman, 1953; Hansel \& Asdell, 1951; Reuber \& Emmerson, 1959). A middle uterine artery arises from the umbilical artery in the cow and the caudal uterine artery is a branch of the artery called urogenital by St Clair (1958), middle haemorrhoidal by Sisson \& Grossman (1953) and vaginal by Preuss (1959).

The results of the present study substantiate the findings of Lange (1959) that there is no cranial uterine artery in the pig. There exists, instead, many minute anastomoses between the artery supplying the uterus and the ovarian artery. In contrast to the minute uterine-ovarian anastomoses, large branches of the uterine artery and the uterine branch of the urogenital artery join directly with each other.

Anderson (1926) stated that in the sow the ovarian artery divided into two branches several centimetres before reaching the hilus of the ovary and that at the hilus each branch split into two to four smaller branches before entering the ovary. It was found in the present study that the ovarian artery divided many times before it reached the hilus of the ovary, the subsequent branches anastomosed with each other as well as with branches from the uterine artery and as many as sixteen coalesced branches were observed to enter the ovary.

Lange (1959) described the veins as following the arteries with the ovarian being the largest vein. The ovarian vein drained most of the uterus, received branches from the mesosalpinx and ovary and emptied into the caudal vena cava above the origin of the ovarian artery from the aorta. The uterine vein followed the uterine artery and anastomosed freely with the ovarian vein. Lange stated that the uterine vein emptied into the common iliac vein. He described the uterine branch of the vaginal (urogenital or urethrogenital) vein as draining the body of the uterus.

The present study did not substantiate the observations of Lange (1959) and Barone et al. (1962) that the uterine vein joined the common iliac. In all animals studied it was found, instead, to enter a vein following the ureter. What appeared initially to be a continuation of the uterine vein medial to the ureter was, in fact, a small vein in close association with the uterine and umbilical 
arteries and draining the tissue immediately surrounding these arteries. This small vein as well as other small veins from the surface of the mesometrium also joined the veins which followed the ureter. The use of the terms utero-ovarian vein instead of ovarian vein, and urogenital artery and vein instead of vaginal artery and vein has been adopted because these terms appear to be more descriptive. Use of the term ovarian vein is in keeping with a parallel nomenclature of the arteries and veins; however, this vein is not only the largest vein draining the uterus, but also receives tubal branches and eventually receives blood from the uterine vein via the ureteric veins in addition to receiving ovarian branches. The urogenital artery and vein give origin not only to a vaginal branch but also to caudal vesical, middle rectal, uterine and urethral branches.

\section{ACKNOWLEDGMENTS}

The authors gratefully acknowledge the assistance of $\mathrm{Dr} \mathrm{A}$. A. Case in taking the radiographs and Dr P. D. Garrett in drawing the text-figures. This study was performed while one of us, S. L. O., was a recipient of a Predoctoral Fellowship from the National Institutes of Health, USPHS. This paper is a contribution from the Missouri Agricultural Experiment Station Journal Series No. 2752. Approved by the Director.

\section{REFERENCES}

Anderson, D. H. (1926) Lymphatics and blood vessels of the ovary of the sow. Contrib. Embryol. Carneg. Instn. 17, 107.

Barone, R., Pavaux, Cl. \& Frapart, P. (1962) Les vaisseaux sanguins de l'appareil genital chez la truie. Bull. Soc. Sci. vét. Lyon, 64, 337.

GerTy, R. (1955) Atlas for applied veterinary anatomy, p. 126. Burgess, Minneapolis.

Hansel, W. \& AsDell, S. A. (1951) Arterial system of the uterus of the cow. F. Dairy Sci. 34, 37.

LANGe, H. (1959) Neue Untersuchungen zur Vaskularisation des Schweineuterus. Diss., Berlin.

Preuss, F. (1959) Die A. vaginalis der Haussäugetiere. Berl. Münch. tierärztl. Wschr. 72, 403.

Reuber, H. W. \& Emmerson, M. A. (1959) Arteriography of the internal genitalia of the cow. F. Amer. vet. med. Ass. 134 (3), 101.

St Crair, L. E. (1958) Anatomy. Diseases of Swine, p. 24. Ed. H. W. Dunne. Iowa State College Press, Ames.

Sisson, S. \& Grossman, J. D. (1953) Anatomy of domestic animals, 4th edn, revised, pp. 728 and 757. Saunders, Philadelphia.

Tobin, C. E. (1944) A radiopaque liquid latex injection medium for blood vessels. Amer. F. Roentgenol. 51, 286. 